\title{
Prevalence of Helicobacter pylori Seropositivity Among Patients Undergoing Bariatric Surgery: A Preliminary Study
}

\author{
Attila Csendes
}

Published online: 15 March 2009

(C) Société Internationale de Chirurgie 2009

I read with great interest the article by Erim et al. [1] about the prevalence of $H$. pylori infection among patients with morbid obesity. I was surprised that our article was not mentioned [2]. We performed a prospective endoscopic study of 426 patients with morbid obesity. It is the only study with pathologic findings at the esophagus, stomach, and duodenum, while $H$. pylori was present at the antrum in $53 \%$ of the patients and at the gastroesophageal junction in $17 \%$ of the patients. Erim et al. performed only serologic studies and no endoscopic findings were reported. I would ask the authors to review more completely the published evidence when performing such a study.

\section{References}

1. Erim T, Cruz-Correa M, Szomstein S, Velis E, Rosenthal R (2008) Prevalence of Helicobacter pylori seropositivity among patients undergoing bariatric surgery: a preliminary study. World J Surg 32:2021-2025

2. Csendes A, Burgos AM, Smok G, Beltrán M (2007) Endoscopic and histologic findings of the foregut in 426 patients with morbid obesity. Obes Surg 17:28-34

\footnotetext{
A. Csendes $(\bowtie)$

Department of Surgery, Clinical Hospital University of Chile,

Santiago, Chile

e-mail: acsendes@redclinicauchile.cl
} 